\title{
Influence of Flooding on Leaf Cell Membranes of Three Latvian Wheat Cultivars (Triticum aestivum (L)).
}

\author{
Nataljja Škute \\ Institute of Life Science and \\ Technologies, Daugavpils University, \\ Parades Str. 1A, 122, Daugavpils, \\ LV-5401, Latvia. \\ natalja.skute@du.lv \\ Aleksandrs Petjukevičs \\ Institute of Life Science and \\ Technologies, Daugavpils University, \\ Parades Str. 1A, 122, Daugavpils, \\ LV-5401, Latvia. \\ aleksandrs.petjukevics@du.lv
}

\author{
Marina Savicka \\ Institute of Life Science and Technol- \\ ogies, Daugavpils University, \\ Parades Str. 1A, 122, Daugavpils, \\ LV-5401, Latvia. \\ marina.savicka@du.lv
}

Nadežda Harlamova

Institute of Life Science and

Technologies, Daugavpils University,

Parades Str. 1A, 122, Daugavpils,

LV-5401, Latvia.

nadjaaa@mail.ru

\author{
Alina Kulbachna \\ Institute of Life Science and \\ Technologies, Daugavpils \\ University, \\ Parades Str. 1A, 122, Daugavpils, \\ LV-5401, Latvia. \\ alinakulb@yahoo.com
}

\begin{abstract}
Flooding occurs in many wheat-growing regions around the world. During flooding, the gas exchange between soil and air decreases and root hypoxia or anoxia is the major cause of plant growth reduction under this stress. The hypoxia stress triggers stimulate the formation of reactive oxygen species (ROS) and induce oxidative stress in plants. The wheat is one of the most important crops in Latvia and in the world. Although wheat is one of the most intolerant crops to soil flooding. To elucidate the mechanisms involved in soil flooding and the tolerance of three Latvian commercial winter wheat (Triticum aestivum L.) cultivars: 'Fredis', 'Reinis', 'Brencis' and the flooding induced changes in electrolyte leakage, MDA production, and carotenoid production evaluated. The results indicate, that content of MDA, which reflect the level of membrane lipid peroxidation, differ, but no significant decrease of MDA concentration in cultivar 'Brencis' caused by increased activity of the antioxidant system. The differences in total carotenoids content in investigated wheat cultivars under simulating natural flooding founded. The most active accumulation of total carotenoids observed in the cultivar 'Reinis'. The results demonstrate increased electrolyte leakage in cell membranes of the first leaves in all investigated wheat cultivars compared to control. Under flooding, the first leaf of wheat influenced by lower water temperature compared to the first leaf of the control group and that decrease the membrane fluidity, which possibly leads to decreased of membrane permeability. This preliminary data shows that one-week flooding influences to the cell membranes of some Latvian winter wheat cultivars, this influence differs, but cultivar 'Brencis' was more tolerant of the flooding.
\end{abstract}

Keywords - carotenoids, flooding stress, malondialdehyde level, membrane permeability

\section{INTRODUCTION}

Flooding is one of the remarkable abiotic stresses in most arable farmland for many crops and occurs over vast regions throughout the world adversely affecting approximately $10 \%$ of the global land area [1], [2]. Climate change models predict an increase in the frequency of flooding events globally. Flooding occurs in many wheat-growing regions throughout the world, especially irrigated and high rainfall environments. About 10-15 million ha of the world's wheat growing areas are affected by flooding each year [3], representing $15-20 \%$ of the 70 million ha annually cultivated for wheat production [4]. Wheat is the most important crop in the world and in Latvia as well and provides approx. $75 \%$ of the total cereal production in Latvia. Flooding negatively affect photosynthesis, wheat growth, development and cause significant reduction of their productivity, and also reduce grain yield of winter wheat by $20-50 \%$ [5].

Soil flooding rapidly depletes soil oxygen and lowers soil redox potential; thereby, the roots suffer a shortage of oxygen and roots aerobic respiration dramatically decreased. This will result in a sharp decline in ATP level. Insufficient energy reduces mineral elements, water absorption, and transportation, thereby, altering diverse aspects of plant metabolism such as accelerating lipid peroxidation and leaf senescence and inhibiting growth [4] - [6]. Membranes are dynamic structures that support numerous biochemical and biophysical reactions. They are also major targets of environmental stresses [7]. The changes frequently related to an increase/decrease in membrane permeability, affecting membrane integrity and cell compartmentation under stress conditions. Malondialdehyde (MDA) is one of the final products of stress-induced membrane lipid peroxidation of polyunsaturated fatty acids [8], and the content of MDA 
reflects the level of membrane lipid peroxidation [9] $12]$.

The hydrophobic core of biomembranes composed of polyunsaturated fatty acids is a potential target of attack of active oxygen species, which may directly lead to membrane degradation. When exposed to flooding, plant cell membranes undergo changes in lipid and fatty acid composition in order to maintain chloroplast function. A direct effect of carotenoid pigments on lipid membranes, in particular, the effect on structural and dynamic properties, seems to decrease the lipid membrane susceptibility to oxidative stress [5].

There is wider genetic diversity intolerance to soil flooding among cultivars of wheat [3], [4]. The tolerance of wheat to flooding depends on the ability to change its morphological and metabolic traits in response to the stress for its survival and growth. Therefore, evaluation of flooding conditions appears to be necessary to conserve tolerant genotypes.

The aim of this work was to evaluate the floodinginduced changes in electrolyte leakage, MDA production, and carotenoids content of three Latvian commercial winter wheat (Triticum aestivum L.) cultivars.

\section{MATERIALS AND METHODS}

\section{Plant material and design of the experiment}

The seeds of three Latvian commercial winter wheat (Triticum aestivum L.) cultivars: 'Fredis', 'Reinis', 'Brencis', from the "State Stende Cereals Breeding Institute", Stende, Latvia obtained.

Etiolated wheat seedlings germinated in dark, on moist filter paper at $26{ }^{\circ} \mathrm{C}$ for $24 \mathrm{~h}$ before being transferred to black soil. Seedlings of equal length transferred to $0.3 \mathrm{~L}$ polyethylene pots containing black soil, seedlings were fixed in small apertures at the top of each container and covered with $10 \mathrm{~mm}$ thick black soil. Containers were kept in a climate chamber (Sanyo, Versatile Environmental Test Chamber) under controlled conditions (16/8h light/ dark cycle at $22 / 22{ }^{\circ} \mathrm{C}$ day/night temperature, relative humidity $80 \%$, and light intensity $15.6 \mu \mathrm{mol} \mathrm{m}^{-2} \mathrm{~s}^{-1}$ ). The 1-week seedling separated into two groups: one group of three winter wheat cultivars continue growth in these conditions, but others group was subject to flooding. After one week of flooding the first leaf was cut; MDA concentration and carotenoids content were measured and the electrolyte leakage was determined.

\section{Measurement of MDA content}

The MDA content determined by the thiobarbituric acid (TBA) reaction as described by Ali et al. [19], with slight modifications. Approximately $0.1 \mathrm{~g}$ leaf was homogenized with $1 \mathrm{ml}$ of $0.1 \%$ trichloroacetic acid (TCA) and centrifuged at 14,000 rpm for $15 \mathrm{~min}$. After centrifugation, $1 \mathrm{ml}$ of the supernatant mixed with 2.5 $\mathrm{ml} 0.5 \%$ TBA in $20 \%$ TCA and incubated $\left(95^{\circ} \mathrm{C}\right)$ for 30 min in a water bath (BioSan). Thereafter, it was cooled immediately on ice to stop the reaction and centrifuged at 10,000 rpm for $30 \mathrm{~min}$. Absorbance at 532 and $600 \mathrm{~nm}$ was determined spectrophotometrically (Cary $50 \mathrm{UV} / \mathrm{Vis}$ Scan, Varian), and MDA concentration was estimated by subtracting the non-specific absorption at $600 \mathrm{~nm}$ from the absorption at $532 \mathrm{~nm}$, using an absorbance coefficient of extinction $\left(155 \mathrm{mM}^{-1} \mathrm{~cm}^{-1}\right)$.

\section{Determination of electrolyte leakage}

The electrolyte leakage determined as described before [11]. The first leaves of three seedlings were immersed in $15 \mathrm{ml}$ of distilled water in a test tube overnight at room temperature. The initial conductivity was determined using a conductivity meter. The tubes were then placed in boiling water for $15 \mathrm{~min}$ and cooled to room temperature. Conductivity was again determined. The electrolyte leakage was calculated as the ratio of conductivity before boiling to that after boiling: $\mathrm{EL}(\%)=\left(\mathrm{C}_{\mathrm{b}}-\mathrm{C}_{\mathrm{w}}\right) /\left(\mathrm{C}_{\mathrm{a}}-\mathrm{C}_{\mathrm{w}}\right)$ * 100 , where $\mathrm{C}_{\mathrm{b}}$ is the ratio of conductivity before boiling, $\mathrm{C}_{\mathrm{a}}$ is the ratio of conductivity after boiling, and $\mathrm{C}_{\mathrm{w}}$ is the conductivity of $\mathrm{dH}_{2} \mathrm{O}$.

\section{Measurement of total carotenoids content}

Leaf material $(0.2 \mathrm{~g})$ homogenized in $80 \%$ acetone (4 ml) with the addition of $\mathrm{MgCO}_{3}(0.05 \mathrm{~g})$. After centrifugation at $14,000 \mathrm{rpm}$ for $15 \mathrm{~min}(\mathrm{x} 3)$ absorbance of each acetone extract of pigments was determined by spectrophotometer (Cary $50 \mathrm{UV} / \mathrm{Vis}$ Scan, Varian), wavelengths: $663.0 \mathrm{~nm} ; 646.0 \mathrm{~nm} ; 470.0 \mathrm{~nm}$. The carotenoids concentrations $(\mathrm{mg} / \mathrm{l})$ were calculated using formulas: $\mathrm{C}_{\text {car }}=\left(1000 \mathrm{D}_{470}-3.27 \mathrm{C}_{\mathrm{a}}-100 \mathrm{C}_{\mathrm{b}}\right) / 229$, where $\mathrm{C}_{\mathrm{a}}$ - chlorophyll A concentrations $\left(\mathrm{C}_{\mathrm{a}}=12.21 \mathrm{D}_{663}-2.81 \mathrm{D}_{646}\right)$, $\mathrm{C}_{\mathrm{b}}$ - chlorophyll $\mathrm{B}$, concentrations, $\mathrm{D}_{663}, \mathrm{D}_{646}, \mathrm{D}_{470}$ - optical density. Amount of total carotenoids was determined according to Lichtenthaler [14].

\section{Statistical analysis}

To determine the reliability of the results of this research by one-way ANOVA was used. The results presented as mean values \pm standard error, with three replications, values of $\mathrm{p}<0.05$ were considered significantly different.

\section{RESULTS AND DISCUSSION}

To evaluate the flooding influence on some wheat (Triticum aestivum L.) cultivars the damage at cell membrane: membrane permeability, membrane lipid peroxidation, and carotenoids, which interact with thylakoid membrane in chloroplasts studied.

Malondialdehyde (MDA) is one of the final products of stress-induced lipid peroxidation of polyunsaturated fatty acids [10] and has been considered as a marker for evaluation of the cell membrane damage under the oneweek flooding stress. Malondialdehyde concentration of three Latvian winter wheat cultivars show (Fig. 1) that lipid peroxidation, as indicated by malondialdehyde content, under oxidative stress caused by flooding varies significantly between wheat cultivars. Malondialdehyde 
concentration of one cultivar - 'Brencis'- decreased after 7 days of flooding by $6 \%\left(0.03 \mu \mathrm{M} \mathrm{g}^{-1}\right)$, two cultivars 'Fredis' and 'Reinis' - increased by 17,3\% (0.09 $\left.\mu \mathrm{M} \mathrm{g}^{-1}\right)$ and $36,2 \%\left(0.15 \mu \mathrm{M} \mathrm{g}^{-1}\right)$ respectively.

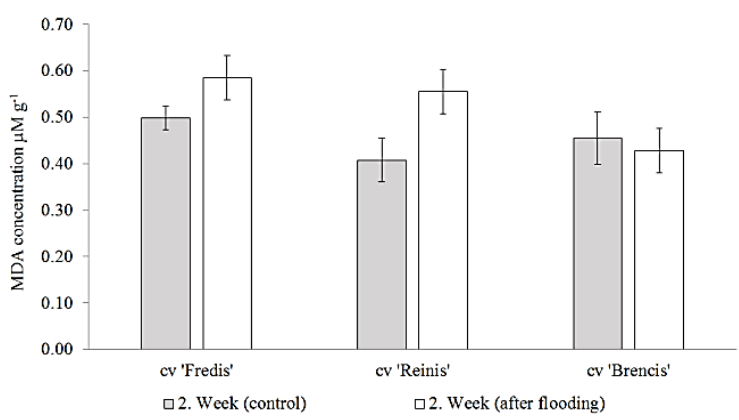

Fig.1. MDA concentration dynamics in the first leaf of three Triticum aestivum (L) cultivars (second week: control and after flooding).

It was shown, that one-week flooding stress decreased electrolyte leakage in cell membranes of the first leaves in all investigated wheat cultivars compared to control (Fig.2) by $14 \%, 51 \%$ and $25 \%$ in 'Fredis', 'Reinis' and 'Brencis' respectively. However, despite the highest membrane permeability in 'Reinis' in the control, the strongest decrease in membrane permeability was observed after one-week flooding stress in comparison with other cultivars.

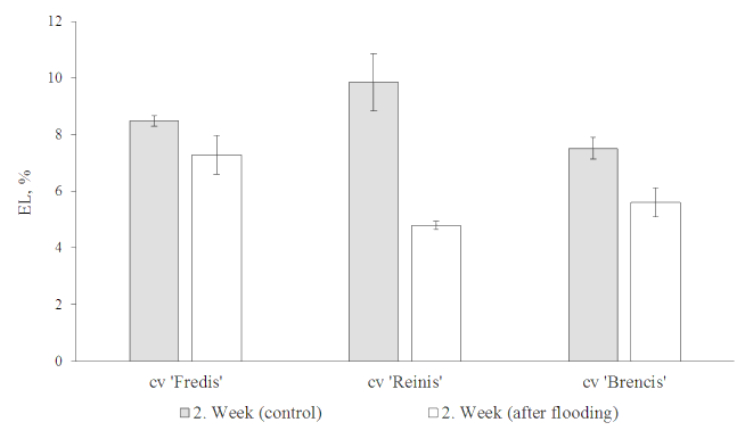

Fig.2. Electrolyte leakage (EL, \%) dynamics in the first leaf of three Triticum aestivum (L) cultivars (second week: control and after flooding).

Carotenoid pigments incorporate to the lipid bilayer system of the thylakoid membrane in chloroplasts. At the end of the first week of modulated seasonal flooding, there was an insignificant accumulation of total carotenoids compering with water non-submerged samples in all wheat cultivars. The differences in total carotenoid content after simulating natural flooding in investigated wheat cultivars found. The changes in the sum of total carotenoids did not exceed $12 \%$ compared to control (in absolute values ranged from 3.12 to 3.54 $\mathrm{mg} / \mathrm{L}$, depending on the wheat cultivar) (Fig. 3). The more active accumulation of total carotenoids was observed in the wheat (Triticum aestivum, L.) cultivar 'Reinis': $11.86 \%$ compared to control (increase on 0.37 $\mathrm{mg} / \mathrm{L}$ in absolute values).

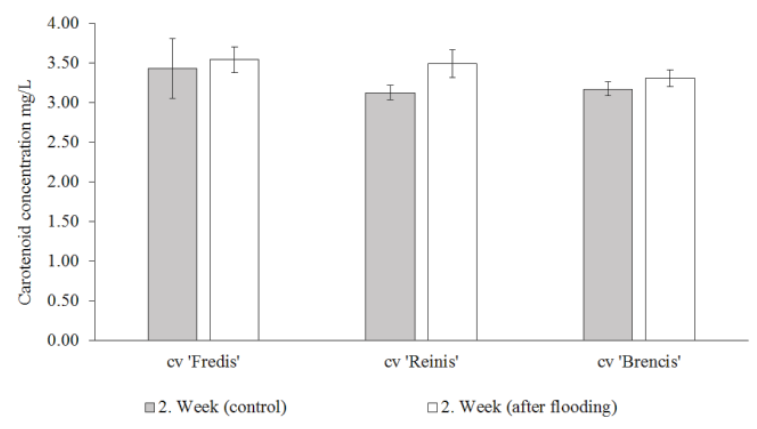

Fig.3. Carotenoid distribution $(\mathrm{mg} / \mathrm{L})$ dynamics in the first leaf of three Triticum aestivum (L) cultivars (second week: control and after flooding).

Flooding occurs in many wheat-growing regions around the world. During flooding, the gas exchange between soil and air decreases, $\mathrm{O}_{2}$ in the soil depleted rapidly, and the soil may become hypoxic or anoxic within a few hours. Root hypoxia or anoxia is the major cause of reduced plant growth under flooding stress [15], [17]. Although wheat is one of the most intolerant crops to soil flooding there is wider genetic diversity intolerance to soil flooding among cultivars of wheat [4].

Exposure of plants to most adverse conditions like hypoxia or anoxia causes oxidative stress, which affects plant growth due to the production of reactive oxygen species (ROS) [16]. Increased ROS levels in plant leaves under flooding stress had been reported previously [12].

Hypoxia stress triggers the formation of ROS and induces oxidative stress in plants. Malondialdehyde (MDA) is one of the final products of stress-induced membrane lipid peroxidation of polyunsaturated fatty acids [8], [19], and the content of MDA reflects the level of membrane lipid peroxidation. Our investigation showed that MDA concentration increased in the first leaves in all investigated wheat cultivars compared to control at the end of the first week of modulated seasonal flooding. These changes of MDA concentration differ in investigated wheat cultivars from $6 \%$ 'Brencis' to $36.2 \%$ 'Reinis'.

An increase of MDA concentration in the first leaf of two wheat cultivars - 'Fredis' and 'Reinis' - in the experimental group indicates oxidative stress caused by flooding. The decrease of MDA concentration of cultivar 'Brencis' may be caused by increased activity of the antioxidant system.

Thus can assume, that cultivar 'Brencis' has more expressing genes encoding enzymes involved in the antioxidative defense system. The tolerance to stress improved by increased antioxidant capacity and decreased membrane lipid peroxidation. Over generations, many plants have mutated and evolved with different mechanisms to counter stress effects. These include a range of different mechanisms such as accumulation of facultative inducible metabolic adaptations, induction of fatty acid desaturases and heat shock proteins, activation of phytochelatin synthase and metallothionein, activation of alternative respiratory pathways, induction of polyamine synthesis, production of antioxidant enzymes and eco-physiological (carbon assimilation) 
adaptations such as increased isoprene synthesis, which includes the large and crucial group of carotenoids [5]. Carotenoids are essential for different plant processes and are potential antioxidants during plant stress. Among the various radicals formed under oxidative conditions in the organism, carotenoids most efficiently react with peroxyl radicals. They generated in the process of lipid peroxidation, and scavenging of this species interrupts the reaction sequence, which finally leads to damage in lipophilic compartments. [13], [20], [21].

The results of our study suggest that flooding insignificantly activate the synthesis of carotenoids, as a response of defensive reaction to one-week flooding [18]. The more active accumulation of total carotenoids observed in the wheat (Triticum aestivum, L.) cultivar 'Reinis'.

The different mechanisms effect on carotenoid pigments in lipid membranes, in particular, the effect on structural and dynamic properties, seems to decrease the lipid membrane susceptibility to oxidative degradation. Carotenoids might act as light harvesters, quenchers and scavengers of triplet state chlorophylls and singlet oxygen species, dissipaters of excess harmful energy during stress condition and membrane stabilizers. The increase in electrolyte leakage usually considered as one of the major causes of increased cell membrane permeability of plants growing under different stresses [18]. Our results did not show the increased electrolyte leakage in cell membranes of the first leaves in all investigated wheat cultivars compared to control. However, despite the highest membrane permeability in cultivar 'Reinis' in control, the strongest decrease in membrane permeability was observed after one-week flooding stress in comparison with other investigated wheat cultivars. Polar carotenoids (zeaxanthin, violaxanthin, and lutein) increase the membrane fluidity in the ordered phase of the membrane and decrease fluidity in the liquid crystalline phase of the membranes formed with phosphatidylcholines [5].

\section{CONCLUSION}

Under flooding stress, the first leaf of wheat influenced by lower water temperature compared with the first leaf of the control group. That decrease membrane fluidity, which can lead to decreased membrane permeability. This preliminary data shows that one-week flooding influences cell membranes of some Latvian winter wheat cultivars. This influence differs in investigated cultivars, but cultivar 'Brencis' was more tolerant of flooding.

\section{REFERENCES}

[1] T. Kozlowski, "Plant Responses to Flooding of Soil," BioSciense, vol. 34, Issue 3, pp. 162-167, 1984. [2] FAO Agriculture, 2002, Available:

http://www.fao.org/waicent/FAOINFO/AGRICULT/ag1/ag11/gaez// nav.html [Accessed March 18, 2009].

[3] K.D. Sayre, M. Van Ginkel, S. Rajaram, I. Ortiz- Monasterio, "Tolerance to waterlogging losses in spring bread wheat: Effect of time of onset on expression," Annu Wheat News, vol. 140, pp. 165 $171,1994$.

[4] T.L. Settler, I. Waters, "Reviews of prospects for germplasm improvement for waterlogging tolerance in wheat, barley and oats," Plant Soil, vol. 253, pp. 1-34, 2003.

[5] W.I. Gruszeckia, K. Strzaykab, "Carotenoids as modulators of lipid membrane physical properties," Biochimica et Biophysica Acta, vol. 1740, pp. 108-115, 2005.

[6] F. Płażek, K.M. Dubert, "Cell membrane permeability and antioxidant activities in the rootstocks of Miscanthus x giganteus as an effect of cold and frost treatment," Journ. of Appl.Botany and Food Quality, vol. 82, pp. 158-162, 2009.

[7] S.R. Pezeshki, "Wetland plant responses to soil flooding," Environmental and Experimental Botany, vol. 46, pp. 299-312, 2001.

[8] Y.B. Dai, Q. Liu, X. Huang, S.Z. Wang, "Flooding-induced membrane damage, lipid oxidation and activated oxygen generation in corn leaves," Plant and Soil, vol. 179, pp. 268-275, 1996,

[9] B. Vartapetian, M. Jackson," Plant Adaptations to Anaerobic Stress. Annals of Botany," vol. 79, pp. 3- 20, 1997.

[10] Y. Leshem, "Membrane phospholipid catabolism and Ca2+ activity in control of senescence," Physiol Plant, vol. 69, pp. 551-559, 1987.

[11] Z. W. Guo Ou, S. Lu, Q. Zhong, "Differential responses of antioxidative system to chilling and drought in four rice cultivars differing in sensitivity," Plant Physiology and Biochemistry. vol. 44, pp. 828-36, 2006

[12] C. Rosenzweig, F. Tubiello, R. Goldberg, E. Mills, J. Bloomfield, "Increased crop damage in the US from excess precipitation under climate change," Global Environmental Change-Human and Policy, vol. 12, pp. 197-202, 2002.

[13] A. Petjukevičs, A. Batjuka, N. Škute, "The impact of different levels of sodium chloride on the quantitative changes of chlorophyll and carotenoids in chloroplasts of Elodea canadensis (Michx. 1803)," Biologija, vol. 61(1), pp. 34-41, 2015.

[14] H.K. Lichtenthaler, "Chlorophylls and carotenoids: pigments of photosynthetic biomembranes," Methods Enzymol, vol. 148, pp. 350-383, 1988.

[15] M.E. Ghobadi, M. Ghobadi, A. Zebarjadi, "The Response of Winter Wheat to Flooding," International Journal of Agricultural and Biosystems Engineering, vol. 5 (6), 2011.

[16] Md. A. Hossain, S. N. Uddin, "Mechanisms of waterlogging tolerance in wheat: Morphological and metabolic adaptations under hypoxia or anoxia," AJCS, vol. 5(9), pp. 1094-1101, 2011.

[17] B. Huang, J.W. Johnson, D.S. Nesmith, D.C. Bridges, "Root and shoot growth of wheat genotypes in response to hypoxia and subsequent resumption of aeration," Crop Sci, vol. 34, pp. 15381544, 2011.

[18] M. Havaux, "Carotenoids as membrane stabilizers in chloroplasts," Trends in plant science," vol. 3(4), pp. 147-151, 1998.

[19] M. B. Ali, E. J. Hahn, K. Y. Paek, "Effects of light intensities on antioxidant enzymes and malondialdehyde content during shortterm acclimatization on micro-propagated Phalaenopsis plantlet," Environmental and Experimental Botany, vol. 54(2), pp. 109-120, 2005.

[20] W. Stahl, H. Sies. "Antioxidant activity of carotenoids," Mol Aspects Med, vol. 24, pp. 345-351, 2003.

[21] A.J. Young, G.M. Lowe. "Antioxidant and prooxidant properties of carotenoids," Arch. Biochem.

Biophys, vol. 385, pp. 20-27, 2001. 